\title{
De relatie tussen de wervingsstrategie van de buurt- sportcoach en kenmerken van bereikte deelnemers aan activiteiten van de buurtsportcoach
}

\author{
Eva Smit · Karlijn Leenaars · Annemarie Wagemakers · Koos van der Velden · Gerard Molleman $\mathbb{D}$
}

Geaccepteerd op: 19 mei 2021 / Published online: 9 juli 2021

(C) The Author(s) 2021

\begin{abstract}
Samenvatting
Inleiding Buurtsportcoaches zijn aangesteld om een verbinding te creëren tussen de eerstelijnszorg en de bewegingssector om inactieve bewoners te stimuleren lichamelijk actief te worden. Buurtsportcoaches gebruiken drie wervingsstrategieën om deze doelgroep te bereiken. Het doel van dit onderzoek was om te achterhalen of buurtsportcoaches met de verschillende wervingsstrategieën andere deelnemers qua beweeggedrag en gezondheidskenmerken bereiken.

Methode De buurtsportcoaches hebben deelnemers voor de activiteiten en het onderzoek geworven via public relations $(n=135)$, een persoonlijke brief $(n=136)$ of een verwijzing $(n=98)$. De deelnemers hebben voor aanvang van de activiteit een fysieke test gedaan en een vragenlijst ingevuld. Met behulp van multilevel-analyses zijn de deelnemers per wervingsstrategie vergeleken op beweegnorm, kwaliteit van leven, motivatie, self-efficacy, morbiditeit en fitheid.
\end{abstract}

Dit artikel is mede gebaseerd op Smit E, Leenaars $\mathrm{K}$, Wagemakers A, Velden K van der, Molleman G. How to recruit inactive residents for lifestyle interventions: participants' characteristics based on various recruitment strategies. Health Promot Int. 2020, Dec 3. Epub 2020 Dec 3.

E. Smit $\cdot$ K. van der Velden $\cdot$ G. Molleman $(\triangle)$

Radboud Institute for Health Sciences, Afdeling

eerstelijnsgeneeskunde, Academische werkplaats AMPHI, Radboudumc, Nijmegen, Nederland

gerard.molleman@radboudumc.nl

K. Leenaars

RIVM, Centrum Gezond leven, Bilthoven, Nederland

\section{A. Wagemakers}

WUR, Social Sciences, Gezondheid en Maatschappij,

Wageningen, Nederland

G. Molleman

afdeling Gezond Leven, GGD Gelderland Zuid, Nijmegen, Nederland
Resultaten De drie groepen verschilden op de beweegnorm $(p=0,002)$. Er waren ook statistisch significante verschillen tussen de drie groepen met betrekking tot acht van de negen dimensies van kwaliteit van leven, motivatie $(p=0,027)$ en het aantal somatische aandoeningen ( $p=0,007)$. Voor geestelijke gezondheid en self-efficacy waren er geen significante verschillen. Op alle dimensies scoort de verwijzingsgroep het minst gunstig.

Conclusie Het werven van deelnemers via een actieve wervingsstrategie, zoals verwijzingen, leverde vooral deelnemers op die vaker inactief zijn en/of risico lopen op chronische ziekten. Zij hebben het meeste baat bij de activiteiten van de buurtsportcoach. De investering in tijd en geld voor een actieve wervingsstrategie is daarom zeer de moeite waard.

Trefwoorden gezondheidsbevordering • eerste lijn . bewegen - buurtsportcoach $\cdot$ wervingsstrategie

\section{The relationship between the Care Sport \\ Connector's recruitment strategy and characteristics of participants in Care Sport Connector activities}

\begin{abstract}
Introduction Care Sport Connectors (CSCs) have been appointed to create a connection between primary care and physical activity (PA) sector to encourage inactive residents to become physically active. Three recruitment strategies have been applied to reach the intended target group. This article examines whether the different recruitment strategies reach other participants in terms of physical activity and health characteristics.

Method Participants were recruited by the CSC through public relations $(n=135)$, a personal letter $(n=136)$ or a referral $(n=98)$ and compared with
\end{abstract}


multi-level analyses based on their PA level, quality of life, motivation self-efficacy, morbidity and fitness, measured before the intervention.

Results The three groups were different in PA level $(p=0.002)$. The outcomes regarding health-related quality of life, motivation $(p=0.027)$ and number of somatic disorders ( $p=0.007$ ) were also significantly different for the three groups, except for the categories of mental health and self-efficacy. For all dimensions, the referral group scored the least favorable.

Conclusion The investment of time and money for an active recruitment strategy, like referrals, is worthwhile because it provides CSCs the opportunity to reach people who are inactive and/or at risk for chronic disease.

Keywords Health promotion · Primary care $\cdot$ Physical activity · Care Sport Connectors · Recruitment strategy

\section{Inleiding}

Met het programma Sport en Bewegen in de Buurt heeft het ministerie van VWS in 2012 het aantal buurtsportcoaches uitgebreid van 2.250 naar 2.900 fte [1]. Buurtsportcoaches ondersteunen gemeenten bij het stimuleren van het gaan en blijven bewegen van inwoners. De uitbreiding maakte het mogelijk om vanaf 2012 buurtsportcoaches niet alleen in te zetten op de jeugd, maar ook op volwassenen en ouderen. Daarmee heeft de overheid een krachtige impuls gegeven aan sporten en bewegen in de buurt, en aan het leggen van een verbinding tussen sport en andere sectoren, zoals onderwijs, welzijn en ook de zorg $[1,2]$.

Het programma Sport en Bewegen in de Buurt maakte het tevens mogelijk dat een deel van deze buurtsportcoaches specifiek aangesteld kon worden om de verbinding tussen de eerstelijnszorg en de sport- en beweegsector te maken. Dit artikel richt zich specifiek op deze buurtsportcoaches die de opdracht hebben om inactieve mensen en patiënten met (risico op) op chronische ziekte uit de eerstelijnszorg te begeleiden naar lokale sport- en beweegactiviteiten. Het stimuleren van leefstijlinterventies om fysiek actiever te worden draagt bij aan een betere gezondheid voor deze groep [3-6].

De buurtsportcoaches hebben daartoe twee belangrijke taken. Een eerste taak is om samen met zorg-, sport- en beweegprofessionals activiteiten te organiseren. Leenaars et al. (in dit nummer) laten zien dat buurtsportcoaches deze samenwerking ook realiseren. Zij doen dit vanuit verschillende werksettings. Een deel is aangesteld binnen de sport- en beweegsector en organiseert zelf beweegactiviteiten of ondersteunt andere organisaties bij het organiseren van beweegactiviteiten. Een ander deel van de buurtsportcoaches werkt vanuit een meer integrale visie op bewegen en gezondheid nauw samen met en krijgt verwijzingen van de welzijns- en de gezondheidssector [7].

Daarnaast is het de taak van deze buurtsportcoach om de gewenste doelgroep, mensen die te weinig bewegen en/of (risico op) chronische ziekten hebben, te bereiken en ervoor te zorgen dat deze groep meer gaat en blijft sporten en bewegen in de buurt. Buurtsportcoaches werven zelf deelnemers voor activiteiten of doen dit in samenwerking met andere organisaties. Ze richten zich daarbij op volwassen buurtbewoners (18+). Inzicht ontbreekt in wie precies bereikt wordt en het werven van de juiste doelgroep is niet eenvoudig [8-11]. Een juiste wervingsstrategie is van belang om ook de juiste doelgroep te kunnen bereiken.

Eerdere onderzoeken leverden inzichten op over het opbouwen van partnerships, inzetten van vormen van beloning, benutten van communicatiekanalen en gebruiken van verwijzingen om de moeilijk te bereiken groep daadwerkelijk te bereiken [8, 12-16]. Deze rapportages en evaluaties geven echter onvoldoende zicht op de mechanismen voor een effectieve wervingsstrategie [17]. In de dagelijkse praktijk van de buurtsportcoach wordt doorgaans - en zeker in de eerste jaren van deze functie - volstaan met het rapporteren van het aantal mensen dat bereikt is. Relevant hierin is te onderzoeken welke mensen met welke wervingsstrategie bereikt worden, en of dit de beoogde doelgroep is [13, 18-20]. Want hoewel het aannemelijk lijkt dat de beoogde doelgroep het makkelijkst bereikt kan worden als deze door de eerste lijn naar de buurtsportcoach doorverwezen wordt, laat de praktijk zien dat een aantal buurtsportcoaches ervan overtuigd is dat ze de beoogde doelgroep ook via andere wervingsstrategieën kunnen bereiken.

De onderzoeksvraag in dit artikel is: wat is het beweeggedrag en wat zijn gezondheidskenmerken van de deelnemers aan de activiteiten van de buurtsportcoach en verschillen deze kenmerken van de deelnemers tussen de gebruikte wervingsstrategieën? Dat geeft zicht op de vraag met welke strategie welke groep deelnemers bereikt wordt en met welke strategie de inactieve en kwetsbare doelgroep het beste bereikt kan worden.

\section{Methode}

\section{De context van het onderzoek}

De beantwoording van deze onderzoeksvraag maakt deel uit van een groter onderzoek naar de buurtsportcoach en de verbinding tussen zorg, sport en bewegen, uitgevoerd in twee promotietrajecten vanuit de WUR en het Radboudumc [21]. Het beschreven evaluatiedesign is een meervoudig caseonderzoek, waarin vijftien buursportcoaches uit negen gemeenten verspreidt over Nederland van 2014 tot het einde van 2016 zijn gevolgd in hun werkzaamheden. De buurtsportcoaches hebben zichzelf aangemeld en willen allen de verbinding tussen zorg, sport en bewegen tot 
stand brengen. Het gaat om een nieuwe invulling van de functie, waarvoor geen blauwdruk aanwezig is. De omstandigheden waaronder ze hun werk vormgeven en uitvoeren verschillen, net als de activiteiten die ze uitvoeren. Het grotere onderzoek is exploratief opgezet met onder andere het doel inzicht te krijgen in de manier waarop de functie van buurtsportcoach wordt uitgevoerd en welke resultaten worden bereikt [21].

Het onderzoek bestaat uit een mixed methodology, wat betekent dat zowel kwantitatieve als kwalitatieve methoden van onderzoek zijn toegepast. We hebben inzicht gekregen in de activiteiten die zijn ingezet door de buurtsportcoaches (zie het artikel van Leenaars et al. in dit nummer).

Voor het beantwoorden van de onderzoeksvraag hebben we de vijftien buurtsportcoaches gevraagd om de deelnemers aan hun activiteiten of die via hun betrokkenheid georganiseerd werden te laten participeren in dit onderzoek. Wanneer er sprake was van een beweeggroep, nam de gehele groep deel aan het onderzoek, met uitzondering van degenen die geen consent gaven, een gering aantal personen. Bij de fitheidstests die de buurtsportcoaches organiseerden, vond het onderzoek direct na de test plaats. Deelnemers werden aselectief benaderd door de eerstvolgende te vragen voor deelname als de onderzoeker klaar was met het includeren van de voorgaande deelnemer. Het werven van de deelnemers heeft in de periode van 2014-2016 plaatsgevonden.

Het werven van voldoende deelnemers was lastig omdat een aantal van de buurtsportcoaches in 2014 net gestart was met hun werkzaamheden. Vaak moesten ze nog beginnen met het organiseren van activiteiten. Om voor dit deel van het onderzoek meer deelnemers te includeren zijn vier extra buurtsportcoaches benaderd. In totaal hebben negentien buurtsportcoaches meegedaan.

Bij de deelnemers aan activiteiten van deze buurtsportcoaches zijn op drie momenten tussen 2014 en 2016 fitheidstests en vragenlijsten afgenomen met een one-group pre-test/post-test design: T0 op 1 à 2 weken voor aanvang van de activiteit, T1 na 6 maanden en T2 na 12 maanden. Voor de onderzoeksvraag die in dit artikel centraal staat hebben we alleen de gegevens uit de eerste onderzoeksronde (T0) gebruikt.

\section{Deelnemers aan het onderzoek}

Van de 402 deelnemers aan de T0-meting zijn er 369 geïncludeerd. In totaal zijn 33 deelnemers uitgesloten omdat ze de vraag niet hebben beantwoord via welke strategie ze geworven zijn. Deze uitsluiting was gedeeltelijk selectief, omdat de uitgesloten deelnemers immigranten waren die vanwege taalproblemen de vragenlijst niet of gedeeltelijk konden invullen. De 33 uitgesloten deelnemers verschilden niet significant van de geïncludeerde deelnemers voor BMI, bloeddruk, kracht en flexibiliteit.
De deelnemers zijn verdeeld in drie groepen op basis van de manier waarop ze werden geworven om deel te nemen aan de activiteit. Iedere buurtsportcoach heeft per beweegactiviteit een van de volgende drie wervingsmethoden toegepast. De eerste groep, de pr-groep, bestond uit 135 deelnemers die werden benaderd via pr-activiteiten, zoals flyers, social media, het ontvangen van de contactgegevens van een buurtsportcoach en mond-tot-mondreclame. Voor de tweede groep, de persoonlijkebriefgroep, werden 136 deelnemers gerekruteerd met een persoonlijke brief van een buurtsportcoach voor deelname aan een fitheidstest als start van een bewegingsprogramma. De woonadressen van volwassenen ouder dan 55 jaar zijn verkregen uit het bevolkingsregister van de gemeente. Deze eerste twee wervingsmethoden zijn vooral uitgevoerd door de buurtsportcoaches, die werken vanuit een sportcontext. De derde groep, de verwijzingsgroep, bestond uit 98 deelnemers die door een professional (huisarts, paramedicus, ggz-medewerker of een welzijnswerker) werden gestimuleerd of gestuurd om deel te nemen aan een interventie of activiteit.

\section{Meetinstrumenten}

Deelnemers ontvingen een boekje met vijf vragenlijsten, de Short Questionnaire to Assess Health-enhancing Physical activity (SQUASH), de kwaliteit van leven-vragenlijst (Rand 36), motivatie (Breq-2), self-efficacy op een vijfpuntslikertschaal en vragenlijst over persoonlijke informatie (leeftijd, geslacht, somatische aandoeningen en op welke rekruteringsstrategie ze reageerden) [22-24]. Het niveau van fysieke activiteit/ bewegen van een deelnemer werd gemeten met de SQUASH [25]. Deze meet de mate en intensiteit van bewegen door te vragen naar de gemiddelde tijdsbesteding per dag en het aantal dagen per week voor het uitvoeren van activiteiten: woon-werkverkeer, bewegen op het werk of op school, huishoudelijk werk en vrije tijd. Scores werden geconverteerd volgens de beweegrichtlijnen en de beweegvariabelen werden gedichotomiseerd. De beweegnorm adviseert om op minstens vijf dagen per week minimaal een half uur matig intensief te bewegen, de fitnorm om minimaal drie keer per week 20 minuten zwaar intensief te bewegen [26]. Aan de combinorm wordt voldaan als men aan de beweegnorm en/of de fitnorm voldoet en voor de sportnorm beoefent men een sportactiviteit [26].

De deelnemers deden een fitheidstest, gebaseerd op het Toronto-model [27]. Daarbij worden vijf factoren gemeten: morfologische factoren, spierkracht en uithoudingsvermogen, motoriek, cardiorespiratoire fitheid en metabolische fitheid. Voor elke factor werden geschikte tests geselecteerd op basis van hun vermogen om functionele fitheid te testen. $\mathrm{Er}$ is daarbij rekening gehouden met de praktische haalbaarheid van uitvoering van de fitheidstest en met een lage belastbaarheid voor ouderen en mensen met een chronische ziekte (of met een verhoogd risico 
daarop). Morfologische factoren, gewicht, lengte, vetpercentage (gemeten met de Omron Body Fat Monitor BF306) en middelomtrek werden respectievelijk tot op $0,1 \mathrm{~kg}, 0,5 \mathrm{~cm}, 0,1 \%$ en $0,5 \mathrm{~cm}$ nauwkeurig geregistreerd. Gewicht en lengte werden gebruikt om de body mass index te berekenen. Schouder-, rugen beenflexibiliteit werd getest met respectievelijk de Straight Leg Raise-test, de Back Scratch-test en de Modified Schober-test [28, 29]. Voor elke test deden de deelnemers drie pogingen. Voor de Modified Schober-test en de Straight Leg Raise-test werd de gemiddelde score geregistreerd. Voor de Back scratchtest werd de beste poging geregistreerd. De metabolische componenten bloeddruk (zittend gemeten), cholesterol en glucose werden gemeten met behulp van de Omron M5-1 en de Accutrend Plus meter, in lijn met het prikprotocol [30]. Spierkracht en uithoudingsvermogen werden gemeten met de Arm Curl, de Chair Stand-test en de Hand Grip Strength-test [28]. Voor dat laatste werd de JAMAR Hand Dynamometer gebruikt. De deelnemers deden twee pogingen, waarvan de maximale score werd genoteerd. De Up and Go-test werd gebruikt om behendigheid, snelheid en dynamische balans voor de motorisch werkende component te testen [28]. De scores werden genoteerd tot op 0,1 seconde nauwkeurig. Voor het meten van cardiorespiratoire fitheid werden twee tests gebruikt: de 6 minuten wandeltest [31] en de Astrand-test. De wandeltest is gebruikt voor ouderen (50+) en allochtonen die niet gewend zijn te fietsen. Om beide scores te vergelijken, hebben we normvergelijkingen gebruikt om de afwijking van de norm voor elke deelnemer als percentage weer te geven [31-33]. Percentages van beide normen werden getransformeerd naar een z-score.

Alle onderdelen van de fitheidstest werden beschreven in een protocol om ervoor te zorgen dat elke testleider de test identiek uitvoerde. Elke testleider werd geïnstrueerd door ES (eerste auteur), die bij $80 \%$ van de fitheidstests ter plaatse was. Bij afwezigheid nam een geïnstrueerde fysiotherapeut het over. Na de fitheidstests ontvingen alle deelnemers de papieren vragenlijst, die thuis of bij de beweegactiviteit is ingevuld. Dit nam ongeveer een uur tijd in beslag. Ze hadden drie weken de tijd om de vragenlijst in te vullen en per post te versturen. Na twee weken is er een herinnering gestuurd. Alle deelnemers gaven na geïnformeerd te zijn toestemming en namen vrijwillig deel aan het onderzoek.

\section{Statistische analyse}

We hebben de deelnemers aan T0 in drie groepen verdeeld op basis van de manier waarop ze geworven zijn. Dit is de onafhankelijke variabele. De deelnemers werden per buurtsportcoach geclusterd. Daarom hebben we een multilevel analyse gebruikt om te testen of kenmerken van deelnemers tussen de drie wervingsstrategieën verschillen.
Dit onderzoek is een exploratief onderzoek waardoor we niet confirmatief willen zijn. Hiervoor gebruiken we voor de continue variabelen een lineair model. Het voldoen aan de beweegrichtlijn, de waarde die is gedichotomiseerd, is geanalyseerd met behulp van een logistisch regressiemodel. Door een mixed model te gebruiken houden we rekening met een clustering in de data van de wervingsmethode en de clustering per buurtsportcoach. De variabelen werden gecorrigeerd voor leeftijd en geslacht. Medicatiegerelateerde variabelen (bloeddruk, cholesterol en bloedglucosespiegel) werden gecorrigeerd voor bijbehorend medicatiegebruik. De variabele voor medisch gebruik werd gedichotomiseerd in ja of nee. Een $p$-waarde van $<0,05$ werd op basis van een tweezijdige test als statistisch significant beschouwd. Een Sidak-post-hocanalyse werd gebruikt om te testen op significante verschillen tussen de drie groepen en houdt rekening met het feit dat er meerdere keren wordt getoetst.

\section{Financiering en ethische aspecten}

Dit onderzoek is gefinancierd door ZonMw, (project nummer 525001002) en geregistreerd in het Nederlandse Trialregister NTR4986 op 14 December 2014.

Dit onderzoek is goedgekeurd door de Medisch Ethische Commissie: CMO Regio Arnhem-Nijmegen (filenummer 2013-492).

\section{Resultaten}

Van alle deelnemers was 71,3\% vrouw en de gemiddelde leeftijd was 61,8 jaar $(s d=14,11)$ (tab. 1). De groepen verschilden niet significant in geslacht en leeftijd. De drie groepen verschilden significant op de beweegnorm $(p=0,002)$. De verwezen groep had met $32,7 \%$ het laagste percentage deelnemers dat voldeed aan de beweegnorm, vergeleken met respectievelijk $45,2 \%$ en $60,3 \%$ van de pr- en persoonlijkebriefgroep. In tegenstelling tot mentale gezondheid en self-efficacy waren de andere uitkomsten met betrekking tot kwaliteit van leven, motivatie $(p=0,027)$ en het aantal somatische aandoeningen $(p=0,007)$ ook significant verschillend $(p<0,05)$ tussen de drie groepen. Op alle dimensies scoorde de verwijzingsgroep het minst gunstig.

De volgende variabelen van de fitheidstest waren significant verschillend voor de drie groepen: middelomtrek $(p=0,012)$, schouderflexibiliteit $(p=0,004)$, beenkracht $(p=0,003)$, armkracht $(p=<0,001)$, snelheid, behendigheid en balans $(p=<0,001)$, en uithoudingsvermogen $(p=<0,004)$. Ook voor deze dimensies scoorde de verwijzingsgroep het minst gunstig.

Post-hocanalyse toonde aan waar de verschillen tussen de drie groepen zitten (tab. 2). De verwijzingsgroep verschilde significant van de andere twee groepen voor de beweegnorm, lichamelijk functioneren, rolbeperking door lichamelijke gezondheid, algemene gezondheid, gezondheidsverandering, het 
Tabel 1 Scores voor beweeggedrag, kwaliteit van leven, motivatie, self-efficacy en fitheid per wervingsstrategie

\begin{tabular}{|c|c|c|c|c|}
\hline & $\mathrm{pr}$ & brief & verwijzing & $p$-waarde \\
\hline vrouw $n(\%)$ & $111(82,2 \%)$ & $81(59,6 \%)$ & $71(72,4 \%)$ & 0,428 \\
\hline leeftijd (jaren) & $59,8 \pm 14,9$ & $67,9 \pm 7,6$ & $53,5 \pm 16,9$ & 0,821 \\
\hline voldoet aan beweegnorm $n^{e}$ & $61(45,2 \%)$ & $82(60,3 \%)$ & $32(32,7 \%)^{\mathrm{a}}$ & 0,002 \\
\hline \multicolumn{5}{|l|}{ kwaliteit van leven $(0-100)^{d}$} \\
\hline - lichamelijke gezondheid & $71,3 \pm 25,0$ & $79 \pm 19,0$ & $62,1^{\mathrm{a}} \pm 23,9$ & 0,003 \\
\hline - sociaal functioneren & $77,9 \pm 23,6$ & $85,4 \pm 19,5$ & $70,9 \pm 24,2$ & 0,040 \\
\hline - rol beperking lichamelijke gezondheid & $75,7 \pm 37,3$ & $81,8 \pm 32,0$ & $50,7^{\mathrm{a}} \pm 44,8$ & 0,001 \\
\hline - rol beperking door emotioneel functioneren & $80,2 \pm 37,2$ & $88,2 \pm 27,3$ & $67,1 \pm 40,5$ & 0,042 \\
\hline - mentale gezondheid & $72,5 \pm 18,6$ & $76,9 \pm 17,2$ & $68,3 \pm 19,4$ & 0,145 \\
\hline - vitaliteit & $62,5 \pm 19,0$ & $67,7 \pm 18,3$ & $53,3^{\mathrm{C}} \pm 20,0$ & 0,029 \\
\hline - pijn & $73,2 \pm 25,5$ & $78,5 \pm 20,4$ & $62,5 \pm 24,9$ & 0,027 \\
\hline - algemene gezondheid & $62,6 \pm 15,7$ & $65 \pm 16,7$ & $49,7^{a} \pm 16,9$ & 0,001 \\
\hline - gezondheidsverandering & $50,4 \pm 17,7$ & $51,3 \pm 16,2$ & $40,5^{a} \pm 18,6$ & 0,005 \\
\hline motivatie $(-25-19)^{d}$ & $9,0 \pm 5,1$ & $8,9 \pm 5,3$ & $6,5^{\mathrm{b}} \pm 5,2$ & 0,027 \\
\hline self-efficacy $(1-5)^{d}$ & $3,2 \pm 0,8$ & $3,1 \pm 0,7$ & $2,9 \pm 0,7$ & 0,464 \\
\hline aantal somatische ziekten ${ }^{\dagger}$ & $1,5 \pm 1,8$ & $1,6 \pm 1,5$ & $2,4^{a} \pm 2,1$ & 0,007 \\
\hline body mass index $\left(\mathrm{kg} / \mathrm{m}^{2}\right)^{\dagger}$ & $29,7 \pm 5,4$ & $27,7 \pm 4,9$ & $32,5 \pm 6,9$ & 0,050 \\
\hline middelomtrek $(\mathrm{cm})^{\dagger}$ & $97,1 \pm 12,2$ & $96,7 \pm 12,9$ & $107,3^{\mathrm{C}} \pm 19,2$ & 0,012 \\
\hline vetpercentage $(\%)^{\dagger}$ & $38,0 \pm 7,5$ & $33,8 \pm 8,4$ & $40,4 \pm 9,2$ & 0,174 \\
\hline glucose $(\mathrm{mmol} / \mathrm{l})^{\dagger}$ & $5,7 \pm 1,8$ & $5,9 \pm 1,6$ & $5,7 \pm 1,7$ & 0,705 \\
\hline cholesterol $(\mathrm{mmol} / /)^{\dagger}$ & $5,5 \pm 1,0$ & $5,8 \pm 1,0$ & $5,2 \pm 1,0$ & 0,198 \\
\hline \multicolumn{5}{|l|}{ bloeddruk $^{\dagger}$} \\
\hline - diastolisch (mm Hg) & $84,9 \pm 10,1$ & $87,3 \pm 10,0$ & $82,9 \pm 11,2$ & 0,199 \\
\hline - systolisch (mm Hg) & $135,9 \pm 18,5$ & $145,7 \pm 17,9$ & $135,3 \pm 17,7$ & 0,149 \\
\hline schouderflexibiliteit $(\mathrm{cm})^{f}$ & $8,7 \pm 10,0$ & $8,3^{a} \pm 9,2$ & $11,8 \pm 11,2$ & 0,004 \\
\hline beenflexibiliteit (graden) & $81,5 \pm 14,7$ & $74,9 \pm 15,3$ & $83,9 \pm 15,0$ & 0,834 \\
\hline rugflexibiliteit (cm) & $20,8 \pm 2,3$ & $20,3 \pm 1,6$ & $20,5 \pm 1,9$ & 0,333 \\
\hline beenkracht $(n)$ & $12,8 \pm 4,1$ & $13,7 \pm 3,2$ & $11,8^{a} \pm 3,8$ & 0,003 \\
\hline $\operatorname{armkracht}(n)$ & $15,4^{a} \pm 4,6$ & $17,7^{\mathrm{a}} \pm 4,1$ & $15,2^{\mathrm{a}} \pm 5,9$ & $<0,001$ \\
\hline handgripkracht (kg) & $59 \pm 18,3$ & $65,4 \pm 20,0$ & $59,5 \pm 23,2$ & 0,124 \\
\hline snelheid, behendigheid, balans $(\mathrm{sec})^{f}$ & $7,3 \pm 2,6$ & $5,8^{a} \pm 1,5$ & $7,4 \pm 2,0$ & $<0,001$ \\
\hline uithoudingsvermogen (z-score) & $-0,3 \pm 0,9$ & $0,5 \pm 0,8$ & $-0,4^{C} \pm 1.0$ & 0,003 \\
\hline \multicolumn{5}{|c|}{ 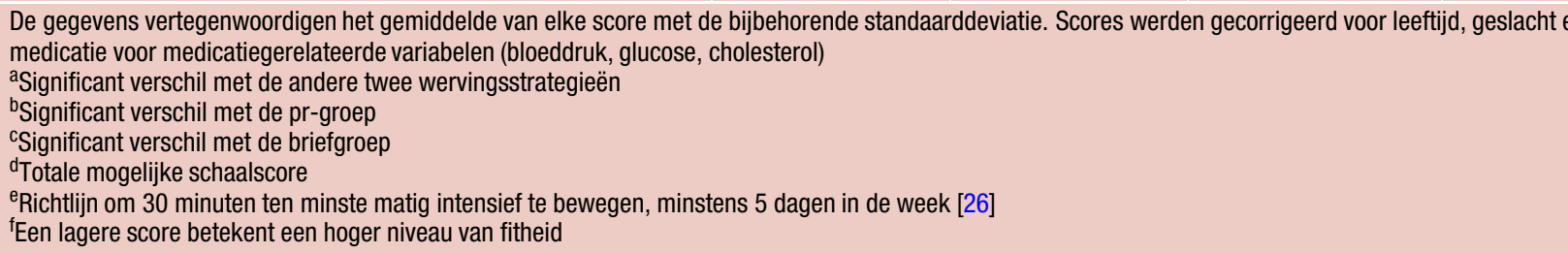 } \\
\hline
\end{tabular}

aantal somatische ziekten, beenkracht en armkracht. De verwijzingsgroep verschilde significant van de prgroep voor motivatie en van de persoonlijkebriefgroep voor vitaliteit, middelomtrek, schouderflexibiliteit, en snelheid, behendigheid en balans.

\section{Beschouwing}

Het doel van dit onderzoek is te onderzoeken of met de verschillende wervingsstrategieën (pr, brief en verwijzing) deelnemers met verschillende kenmerken worden bereikt en met welke strategie de groep deelnemers die te weinig bewegen en/of (ri- sico op) chronische ziekten hebben het meest wordt bereikt. De pr-groep kan worden omschreven als een groep die zeer gemotiveerd was om lichamelijk actiever te worden. Ze scoorden op kwaliteit van leven binnen het normale bereik en waren matig fit. De persoonlijkebriefgroep, vooral gerekruteerd voor een fitheidstest, ervoer over het algemeen een goede kwaliteit van leven en was voor het merendeel fit. De verwijzingsgroep was minder gemotiveerd om lichamelijk actief te worden, ervoer een lagere kwaliteit van leven en was minder fit in vergelijking met de andere twee groepen. De groep met deelnemers die door een zorgprofessional waren verwezen scoorde 


\section{Wetenschappelijk artikel}

Tabel 2 Post-hocanalyse voor de drie wervingsstrategieën

\begin{tabular}{|c|c|c|c|c|c|c|c|c|}
\hline & wervingsstrategie & $n(\%)$ & \multicolumn{3}{|l|}{ oddsratio (95\%-Bl) } & \multicolumn{3}{|c|}{$p$-waarde } \\
\hline \multirow{5}{*}{$\begin{array}{l}\text { voldoet aan bewee- } \\
\text { grichtlijn }\end{array}$} & $\mathrm{pr}$ & $61(45,2 \%)$ & & & & & & \\
\hline & brief & $82(60,3 \%)$ & \multicolumn{3}{|l|}{$2,0(0,1-1,3)$} & \multicolumn{3}{|l|}{0,026} \\
\hline & verwijzing & $32(32,7 \%)$ & \multicolumn{3}{|l|}{$0,6(0,3-1,1)$} & \multicolumn{3}{|l|}{0,113} \\
\hline & & \multirow{2}{*}{$\begin{array}{l}\text { gemiddelde }{ }^{a} \\
(95 \%-B I)\end{array}$} & \multicolumn{3}{|c|}{ gemiddelde verschil (95\%-BI) } & \multicolumn{3}{|c|}{$P$-waarde } \\
\hline & & & $P R$ & Brief & Verwijzing & $P R$ & Brief & Verwijzing \\
\hline \multirow[t]{3}{*}{ lichamelijke gezondheid } & $\mathrm{pr}$ & $69,6(62,1-77,1)$ & - & - & - & - & - & - \\
\hline & brief & $77,8(67,2-88,3)$ & $8,1(-5,6-21,9)$ & - & - & 0,373 & - & - \\
\hline & verwijzing & $60,2(52,6-67,9)$ & $-9,4(-18,4-0,3)$ & $-17,5(-30,9-4,1)$ & - & 0,039 & 0,007 & - \\
\hline \multirow[t]{3}{*}{ sociaal functioneren } & $\mathrm{pr}$ & $76,7(70,4-83,1)$ & - & - & - & - & - & - \\
\hline & brief & $82,4(72,0-92,0)$ & $5,7(-7,3-18,7)$ & - & - & 0,565 & - & - \\
\hline & verwijzing & $70,1(63,5-76,8)$ & $-6,6(-15,5-2,3)$ & $-12,3(-24,7-0,2)$ & - & 0,210 & 0,054 & - \\
\hline \multirow{3}{*}{$\begin{array}{l}\text { rol beperking door } \\
\text { lichamelijke gezondheid }\end{array}$} & $\mathrm{pr}$ & $69,4(56,0-80,7)$ & - & - & - & - & - & - \\
\hline & brief & $80,2(63,4-97,0)$ & $10,8(-11,8-33,5)$ & - & - & 0,511 & - & - \\
\hline & verwijzing & $49,4(47,6-61,3)$ & $-20,0(-35,3-4,6)$ & $-30,8(-52,7-8,9)$ & - & $0 / 006$ & 0,004 & - \\
\hline \multirow{3}{*}{$\begin{array}{l}\text { rol beperking door } \\
\text { emotioneel functioneren }\end{array}$} & $\mathrm{pr}$ & $73,9(62,5-85,3)$ & - & - & - & - & - & - \\
\hline & brief & $86,1(69,5-102,6)$ & $12,2(-9,4-33,8)$ & - & - & 0,400 & - & - \\
\hline & verwijzing & $64,9(52,9-76,8)$ & $-9,0(-23,5-5,4)$ & $-21,2(-42,5-0,0)$ & - & 0,348 & 0,051 & - \\
\hline \multirow[t]{3}{*}{ vitaliteit } & $\mathrm{pr}$ & $61,7(56,5-66,8)$ & - & - & - & - & - & - \\
\hline & brief & $65,2(56,9-73,4)$ & $3,5(-7,7-14,6)$ & - & - & 0,745 & - & - \\
\hline & verwijzing & $54,8(49,4-60,1)$ & $-6,9(-14,3-0,5)$ & $-10,4(-20,7-0,0)$ & - & 0,078 & 0,049 & - \\
\hline \multirow[t]{3}{*}{ pijn } & $\mathrm{pr}$ & $71,2(64,3-78,1)$ & - & - & - & - & - & - \\
\hline & brief & $75,6(65,7-85,6)$ & $4,4(-9,3-18,1)$ & - & - & 0,788 & - & - \\
\hline & verwijzing & $62,5(55,3-69,8)$ & $-8,7(-18,3-0,9)$ & $-13,1(-26,5-0,3)$ & - & 0,087 & 0,056 & - \\
\hline \multirow[t]{3}{*}{ algemene gezondheid } & $\mathrm{pr}$ & $62,3(58,6-66,0)$ & - & - & - & - & - & - \\
\hline & brief & $65,0(57,9-72,1)$ & $2,7(-6,3-11,6)$ & - & - & 0,703 & - & - \\
\hline & verwijzing & $49,6(45,4-53,9)$ & $-12,7(-19,1-6,3)$ & $-15,3(-23,3-7,4)$ & - & 0,000 & $0 / 001$ & - \\
\hline \multirow[t]{3}{*}{ gezondheidsverandering } & $\mathrm{pr}$ & $49,6(45,3-54,0)$ & - & - & - & - & - & - \\
\hline & brief & $51,5(45,6-57,5)$ & $1,9(-7,0-10,8)$ & - & - & 0,916 & - & - \\
\hline & verwijzing & $40,5(35,7-45,4)$ & $-9,1(-16,2-2,0)$ & $-11,0(-20,0-2,1)$ & - & 0,007 & 0,012 & - \\
\hline \multirow[t]{3}{*}{ motivatie } & $\mathrm{pr}$ & $9,1(7,8-10,5)$ & - & - & - & - & - & - \\
\hline & brief & $8,7(6,8-10,6)$ & $-0,5(-3,2-2,3)$ & - & - & $0 / 953$ & - & - \\
\hline & verwijzing & $6,8(5,3-8,2)$ & $-2,4(-4,4-0,3)$ & $-1,9(-4,6-0,8)$ & - & 0,017 & 0,237 & - \\
\hline \multirow{3}{*}{$\begin{array}{l}\text { aantal somatische } \\
\text { ziekten }(n)^{b}\end{array}$} & $\mathrm{pr}$ & $1,7(1,4-2,1)$ & - & - & - & - & - & - \\
\hline & brief & $1,6(0,5-2,7)$ & $-0,1(-1,2-0,9)$ & - & - & 0,925 & - & - \\
\hline & verwijzing & $2,9(2,5-3,3)$ & $1,2(0,6-1,8)$ & $1,3(0,5-2,2)$ & - & $<0,001$ & 0,004 & - \\
\hline \multirow[t]{3}{*}{ middelomtrek $(\mathrm{cm})^{\mathrm{b}}$} & $\mathrm{pr}$ & $100,5(95,5-105,4)$ & - & - & - & - & - & - \\
\hline & brief & $95,9(89,0-102,7)$ & $-4,6(-13,6-4,4)$ & - & - & 0,513 & - & - \\
\hline & verwijzing & $105,6(100,5-110,6)$ & $5,1(-0,6-10,8)$ & $9,7(0,9-18,5)$ & - & 0,093 & 0,026 & - \\
\hline schouderflexibiliteit (cm) & $\mathrm{pr}$ & $11,4(8,7-14,1)$ & - & & - & - & - & - \\
\hline & brief & $6,0(2,2-9,8)$ & $-5,4(-10,7-0,7)$ & - & - & 0,046 & - & - \\
\hline & verwijzing & $13,4(10,5-16,2)$ & $2,0(-1,9-5,8)$ & $7,3(2,1-12,6)$ & - & 0,524 & 0,004 & - \\
\hline beenkracht $(n)$ & $\mathrm{pr}$ & $12,7(11,5-13,9)$ & - & - & - & - & - & - \\
\hline & brief & $14,1(12,5-15,8)$ & $1,4(-0,8-3,6)$ & - & - & 0,297 & - & - \\
\hline & verwijzing & $11,3(10,1-12,5)$ & $-1,4(-2,9-0,4)$ & $-2,9(-5,0-0,7)$ & - & 0,060 & 0,005 & - \\
\hline armkracht $(n)$ & $\mathrm{pr}$ & $15,0(13,4-16,7)$ & - & - & - & - & - & - \\
\hline & brief & $18,3(16,0-20,5)$ & $3,3(0,4-6,1)$ & - & - & 0,020 & - & - \\
\hline & verwijzing & $13,4(11,8-15,1)$ & $-1,6(-3,3-0,2)$ & $-4,8(-7,6-2,1)$ & - & 0,089 & $<0,001$ & - \\
\hline
\end{tabular}


Tabel 2 (Vervolg)

\begin{tabular}{|c|c|c|c|c|c|c|c|c|}
\hline \multirow{4}{*}{$\begin{array}{l}\text { snelheid, behendigheid } \\
\text { en balans (sec) })^{b}\end{array}$} & \multirow{2}{*}{$\begin{array}{l}\text { wervingsstrategie } \\
\mathrm{pr}\end{array}$} & \multirow{2}{*}{$\begin{array}{l}n(\%) \\
\quad 7,5(6,9-8,1)\end{array}$} & \multicolumn{3}{|l|}{ oddsratio (95\%-BI) } & \multicolumn{3}{|c|}{$p$-waarde } \\
\hline & & & - & - & - & - & - & - \\
\hline & brief & $5,6(4,7-6,5)$ & $-1,9(-3,0-0,8)$ & - & - & $<0,001$ & - & - \\
\hline & verwijzing & $7,9(7,2-8,5)$ & $0,4(-0,4-1,1)$ & $2,3(1,2-3,3)$ & - & 0,559 & $<0,001$ & - \\
\hline \multirow{3}{*}{$\begin{array}{l}\text { uithoudingsvermogen } \\
\text { (z-score) }\end{array}$} & $\mathrm{pr}$ & $-0,3(-0,6-0,1)$ & - & - & - & - & - & - \\
\hline & brief & $0,2(-0,2-0,7)$ & $0,5(-0,7-1,1)$ & - & - & 0,100 & - & - \\
\hline & verwijzing & $-0,5(-0,9-0,2)$ & $-0,3(-0,6-0,1)$ & $-0,8(-1,4-0,2)$ & - & 0,250 & 0,003 & - \\
\hline
\end{tabular}

minder gunstig dan de andere twee groepen. Hoewel elke wervingsstrategie deelnemers bereikte die tot de gewenste doelgroep behoorden (inactieve mensen en/of mensen met een (risico op) chronische ziekte), bereikte de verwijzingsgroep deze groep het meest frequent.

Eerdere onderzoeken lieten zien dat de mate en intensiteit van bewegen, fitheid en kwaliteit van leven afnemen met het ouder worden [22, 28, 34-36]. Het is opmerkelijk dat de deelnemers die via verwijzing werden geworven het jongst waren en tegelijkertijd het minst aan de beweegnormen voldeden, het minste fit waren en de minste kwaliteit van leven rapporteerden. Zij lijden ook aan meer somatische ziekten. Dit sluit aan bij bevindingen in de literatuur dat de mate van (ervaren) gezondheid een sterke voorspeller is van en correleert met beweegnormen en fitheid [37-39].

Meer inzicht in het effect van wervingsstrategieën is voor gezondheidsbevorderende interventies relevant. We kunnen een onderscheid maken tussen actieve en passieve werving. Actieve werving verwijst naar directe interactie met potentiële deelnemers via persoonlijk contact [40]. Passieve werving kent geen directe interactie en kan bijvoorbeeld de vorm hebben van flyers en websites [40] of zoals in ons geval ook persoonlijke brieven, geselecteerd vanuit het gemeentelijke bevolkingsregister. Met beperkte inspanning wordt een groot aantal mensen bereikt. Eerdere onderzoeken toonden aan dat passieve wervingsstrategieën om deze reden kostenefficiënter zijn [40, 41]. Maar uit ons onderzoek blijkt dat de buurtsportcoach met deze passieve vormen van werving de doelgroep met overgewicht en andere lichamelijke klachten nauwelijks bereikt. Die bevinding sluit aan bij die van andere onderzoeken. Passieve wervingsstrategieën bereiken vaker lichamelijk actieve deelnemers met een hogere sociaaleconomische status [42, 43]. Ons onderzoek en eerdere onderzoeken tonen aan dat actieve wervingsstrategieën, zoals doorverwijzing, meer inactieve, en/of chronisch zieke en deelnemers met een hogere BMI bereiken [40-42, 44]. Het aanbod van de leefstijlinterventie dient daarop afgestemd te zijn.

\section{Sterke punten en beperkingen}

Dit onderzoek geeft inzicht in de mensen die bereikt worden met activiteiten van de buurtsportcoach. Dat helpt buurtsportcoaches en hun leidinggevenden om een adequate wervingsstrategie te bepalen. Een sterk punt is dat we 402 deelnemers konden includeren.

Er zijn een paar beperkingen waarmee we rekening moeten houden bij de interpretatie van de resultaten. Er zijn verschillen in het aantal deelnemers dat iedere buurtsportcoach voor het onderzoek heeft aangeleverd. Dat betekent dat we de representativiteit van de steekproef niet kunnen garanderen. De buurtsportcoaches registreerden hun activiteiten en hun deelnemers doorgaans onvoldoende. Niet elke bereikte deelnemer werd in het onderzoek meegenomen en niet alle geïncludeerde deelnemers begonnen met een beweegprogramma. Anderzijds vertegenwoordigt ons onderzoek een reële praktijksituatie en daarom is het een goede verkenning. Het is wel aannemelijk dat het werven van deelnemers tegenwoordig gestructureerder vorm krijgt dan ten tijde van dit onderzoek in 2014 en 2015.

Buurtsportcoaches boden verschillende vormen van sport en beweegstimulering aan. De aard van de activiteiten is van invloed op de keuze om al of niet deel te nemen. In bijna alle gevallen ging het om een combinatie van verschillende sporten/ beweegvormen, die in groepsverband zijn aangeboden. Een uitzondering vormt de persoonlijkebriefgroep, die kreeg ook specifieke sportactiviteiten aangeboden.

Er zijn drie wervingsmethoden gebruikt, die op iedere locatie door de eigen buurtsportcoach zijn vormgegeven. Ook de verwijzing naar de activiteiten van de buurtsportcoach is door zorgprofessionals op een eigen wijze gedaan. De vorm en inhoud van het advies dat de zorgprofessional heeft gegeven, kunnen verschillen. Ook kan van invloed zijn welke zorgprofessional het advies heeft gegeven. Mogelijk heeft een huisarts meer invloed dan een paramedicus.

In dit onderzoek hebben we verschillende vragenlijsten gebruikt die zijn gebaseerd op zelfrapportage van respondenten. De gekozen vragenlijsten worden veel gebruikt en zijn getest op validiteit en betrouwbaarheid [22-25]. Een beperking blijft dat elke vragen- 
lijst en zelfs elk item door de respondent kan worden over- of onderschat.

\section{Conclusie}

Ons onderzoek toonde aan dat wervingsstrategieën verschillende doelgroepen bereiken.

De investering in tijd en geld voor een actieve wervingsstrategie, zoals verwijzingen, is de moeite waard omdat daarmee vaker deelnemers worden bereikt die inactief zijn en/of risico lopen op chronische ziekten.

Deze aanpak kost tijd en buurtsportcoaches zijn afhankelijk van andere professionals voor het slagen van een actieve wervingsstrategie. Buurtsportcoaches moeten daarom ook meer beoordeeld worden op het type deelnemers dat ze bereiken dan op het aantal deelnemers dat ze bereiken. Uit eerder onderzoek is gebleken dat een geïntegreerde aanpak voor de inbedding van de buurtsportcoachfunctie, waarbij buurtsportcoaches samenwerken met eerstelijnszorgprofessionals, nuttig is voor het opzetten van een verwijssysteem met eerstelijnszorgprofessionals [7].

Toekomstige onderzoeken zouden zich moeten richten op redenen waarom minder deelnemers zich inschrijven voor een beweegprogramma na actieve werving en hoe dit soort wervingsstrategieën verbeterd kan worden.

Dankbetuiging We danken onze partners, in het bijzonder het Kenniscentrum Sport, de Vereniging Sport en Gemeenten (VSG), het Koninklijk Nederlands Genootschap voor Fysiotherapie (KNGF), de Regionale Ondersteuningsstructuren gericht op de eerstelijnszorg (ROS) en NOC*NSF, voor hun input en ondersteuning.

Open Access This article is licensed under a Creative Commons Attribution 4.0 International License, which permits use, sharing, adaptation, distribution and reproduction in any medium or format, as long as you give appropriate credit to the original author(s) and the source, provide a link to the Creative Commons licence, and indicate if changes were made. The images or other third party material in this article are included in the article's Creative Commons licence, unless indicated otherwise in a credit line to the material. If material is not included in the article's Creative Commons licence and your intended use is not permitted by statutory regulation or exceeds the permitted use, you will need to obtain permission directly from the copyright holder. To view a copy of this licence, visit http://creativecommons.org/licenses/by/4.0/.

\section{Literatuur}

1. Ministerie van Volksgezondheid WeS. Programma Sport en Bewegen in de Buurt. Den Haag: Arko Sports Media; 2011.

2. Ministerie van Volksgezondheid WeS. Landelijke nota gezondheidsbeleid 'Gezondheid dichtbij. Den Haag: Ministerievan Volksgezondheid; 2011.

3. Kirk S, Penney T, McHugh T-L, et al. Effective weight management practice: a review of the lifestyle intervention evidence. Int JObes. 2012;36(2):178-85.

4. Lv N, Azar KM, Rosas LG, et al. Behavioral lifestyle interventions for moderate and severe obesity: a systematic review. PrevMed. 2017;100:180-93.
5. Bergeron CD, Tanner AH, Friedman DB, et al. Physical activity communication: a scoping review of the literature. Health PromotPract. 2019;20(3):344-53.

6. GrimmettC, CorbettT, BrunetJ, etal. Systematic review and meta-analysis of maintenance of physical activity behaviour change in cancer survivors. Int J Behav Nutr Phys Act. 2019;16(1):1-20.

7. Leenaars K, Velden-Bollemaat E van der, Smit E, et al. The operational context of care sport connectors in the Netherlands. Health Promot Int. 2018;33(4):622-34.

8. Peck LE, Sharpe PA, Burroughs EL, et al. Recruitment strategies and costs for a community-based physical activity program. Health Promot Pract. 2008;9(2):191-8.

9. Boutaugh ML. Arthritis Foundation community-based physical activity programs: effectiveness and implementation issues. Arthritis Care Res. 2003;49(3):463-70.

10. Deakin University's Centre for Physical Activity and Nutrition Research. Identifying effective strategies to increase recruitmentand retention in community-basedhealth promotion programs. Melbourne: Deakin University's Centre for Physical Activity and Nutrition Research;2012.

11. Leenaars K, Smit E, Wagemakers A, et al. The role of the care sport connector in the Netherlands. Health Promot Int. 2016;33(3):422-35.

12. Carroll JK, Yancey AK, Spring B, et al. What are successful recruitment and retention strategies for underserved populations? Examining physical activity interventions in primary care and community settings. Transl Behav Med. 2011;1(2):234.

13. Jiwa M, Dadich A, Sriram D, et al. Effective recruitment strategies in primary care research: a systematic review. Qual Prim Care. 2012;20(2):115-23.

14. Leemrijse C, Bakker D, Ooms L. Collaboration of general practitioners and exercise providers in promotion of physical activity: a written survey among general practitioners. BMCFam Pract. 2015;16:96.

15. Research CfPAaN. Research CfPAaN. Identifying effective strategies to increase recruitment and retention in community-based health promotion programs. Melbourne: Deakin University's Centre for Physical Activity and Nutrition Research; 2012.

16. Bonevski B, Randell M, Paul C, et al. Reaching the hard-toreach: a systematic review of strategies for improving health and medical research with socially disadvantaged groups. BMCMed Res Methodol. 2014;14(1):1-29.

17. Cooke R, Jones A. Recruiting adult participants to physical activity intervention studies using sport: a systematic review. BMJ Open Sport Exerc Med. 2017;3(1):e231.

18. Glasgow RE, Vogt TM, Boles SM. Evaluating the public health impact of health promotion interventions: the REAIM framework. Am J Public Health. 1999;89(9):1322-7.

19. UyBico SJ, Pavel S, Gross CP. Recruiting vulnerable populations into research: a systematic review of recruitment interventions. JGen Intern Med. 2007;22(6):852-63.

20. Treweek S, Mitchell E, Pitkethly M, et al. Strategies to improve recruitment to randomised controlled trials. Cochrane Database Syst Rev. 2010;4:MR13.

21. Smit E, Leenaars K, Wagemakers M, et al. Evaluation of the role of care sport connectors in connecting primary care, sport, and physical activity, and residents' participation in the Netherlands: study protocol for a longitudinal multiple case study design. BMC Public Health. 2015;15(1):510.

22. Zee K van der, Sanderman R. RAND-36. Groningen: Northern Centre for Health Care Research, University of Groningen; 1993. pag. 28. 
23. Markland D, Tobin V. A modification to the behavioural regulation in exercise questionnaire to include an assessment of amotivation. J Sport Exerc Psychol. 2004;26(2):191-6.

24. Resnick B, Jenkins LS. Testing the reliability and validity of the self-efficacy for exercise scale. Nurs Res. 2000;49(3):154-9.

25. Ooijendijk W, Wendel-Vos W, Vries S. Advies concensus vragenlijsten Sport en Bewegen. Hoofddorp: TNO Kwaliteit van Leven; 2007.

26. Kemper HCG, Ooijendijk WTM, Stiggelbout M. Consensus over de Nederlandse norm voor gezond bewegen. Tijdschr Gezondheidswet. 2000;78(3):180-3.

27. Bouchard C, Shephard RJ. Physical activity fitness and health: the model and key concepts. In: Bouchard C, Shephard RJ, Stephens T, redactie. Physical activity fitness and health: international proceedings and consensus statement. Champaign: Human Kinetics; 1994. pag. 77-88.

28. Rikli RE, Jones CJ. Development and validation of a functional fitness test for community-residing older adults. JAging Phys Act. 1999;7(2):129-61.

29. Macrae I, Wright V. Measurement of back movement. Ann RheumDis. 1969;28(6):584.

30. Vilans. Protocollenboek Voorbehouden en Risicovolle en Overige handelingen. Utrecht: Vilans; 2012.

31. Wasserman K, Hansen JE, Sue DY, etal. Principles of exercise testing and interpretation. J Cardiopulm Rehabil Prev. 1987;7(4):189.

32. Beekman E, Mesters I, Gosselink R, et al. The first reference equations for the 6 -minutewalkdistance overa 10 m course. Thorax. 2014;69(9):867-8.

33. Myers J, Kaminsky LA, Lima R, et al. A reference equation for normal standards for VO2 max: analysis from the Fitness Registry and the Importance of Exercise National Database (FRIEND registry). Prog Cardiovasc Dis. 2017;60(1):21-9.
34. Hallal PC, Andersen LB, Bull FC, et al. Global physical activitylevels: surveillance progress, pitfalls, and prospects. Lancet. 2012;380(9838):247-57.

35. Nelson G, Amio JL, Prilleltensky I, et al. Partnerships for implementing school and community prevention programs. JEduc Psychol Consult. 2000;11(1):121-45.

36. RIVM. Een gezonder Nederland. Volksgezondheid Toekomst Verkenning 2014. Bilthoven: RIVM; 2014.

37. Hollander E de, Milder I, Proper KI. Beweeg- en sportgedrag van mensen met een chronische aandoening of lichamelijke beperking. Bilthoven: RIVM;2015.

38. Malmberg JJ, Miilunpalo SI, Vuori IM, et al. A health-related fitness and functional performance test battery for middleaged and older adults: feasibility and health-related content validity. Arch Phys Med Rehabil. 2002;83(5):666-77.

39. Suni JH, Oja P, Miilunpalo SI, et al. Health-related fitness test battery for adults: associations with perceived health, mobility, and back function and symptoms. Arch Phys Med Rehabil. 1998;79(5):559-69.

40. Estabrooks P, You W, Hedrick V, et al. A pragmatic examination of active and passive recruitment methods to improve the reach of community lifestyle programs: the Talking Health Trial. Int J Behav Nutr Phys Act. 2017;14(1):7.

41. Lee RE, McGinnis KA, Sallis JF, et al. Active vs. passive methods of recruiting ethnic minority women to a health promotion program. Ann Behav Med. 1997;19(4):378-84.

42. Cooke R, Jones A. Recruiting adult participants to physical activity intervention studies using sport: a systematic review. BMJ Open Sport Exerc Med. 2017;3(1):e231.

43. Martinson BC, Crain AL, Sherwood NE, et al. Population reach and recruitment bias in a maintenance RCT in physicallyactiveolderadults. JPhysActHealth. 2010;7(1):127-35.

44. Yancey AK, Miles OL, McCarthy WJ, et al. Differential response to targeted recruitment strategies to fitness promotion research by African-American women of varying body mass index. Ethn Dis. 2001;11(1):115. 